\title{
Regional landslide early warning using rainfall characteristics
}

\author{
J. Oh, Y. Son, Y. Park, Y. Song \& M. Jung \\ National Disaster Management Institute, \\ Ministry of Public Safety and Security, Korea
}

\begin{abstract}
In order to reduce damage by landslides, an early warning system can be one of the effective countermeasures based on the early detection of landslide occurrence and, therefore, preemptive early evacuation of residents from a landslide prone area. Early detection of landslide indication in a broad natural terrain can be performed by monitoring of rainfall in real time or in near-real time. Based on the real time rainfall data, this study suggested a method to warn of landslides by the application of a tracking line of rainfall. The method makes it possible to set up warning criteria of landslides considering local rainfall characteristics in the summer. This study suggested a method of landslide early warning based on the regional rainfall conditions.
\end{abstract}

Keywords: landslide, rainfall threshold, early warning system, slope disaster.

\section{General instructions}

Every year, Korea suffers from various seasonal natural hazards, which cause tremendous property damage and human losses. Major types of natural hazards in Korea are typhoon and heavy rains, but an earthquake is rare. Another natural hazard, drought, causes adverse impacts on agricultural lands, but the actual damage can be hard to measure. Korean economic and social development in the last few decades has led to a number of populated and quickly industrialized cities. Modernized, industrialized, and urbanized Korean cities show a somewhat different trend from previous cases in terms of disaster characteristics.

A variety of disasters are known and large-scale disasters are reported that are not influenced by time and national or regional borders because of urbanization and densification in modern society. For example, the collapse of the 
Samphoong department store in 1995 and the impact of Typhoon Rusa in 2002 well illustrate the changing face of disasters in Korea. The Indian Ocean tsunami disaster in Asia and Cyclone Nargis in Myanmar are recent warnings for disaster managers. In the future, vulnerability will be increased because of difficulties in risk prediction and efficient response, the aging effect of infrastructures and the probable increase of new societal disturbance such as failure of information and communication systems (Park et al. [1]).

In Korea, human and property damage occur every year due to geological disasters. Especially, slope failure-related disasters that are the result of heavy rainfall due to the typhoon and monsoon from July to September. Types of slope-related disasters include cut-slope failure along the roads, natural terrain failure in mountain areas, and retaining structure failures in the residential areas. The human vulnerability resulting from these geological hazards has been increasing as a function of industrialization and population growth.

Countermeasures to these disasters, however, are limited to field survey after disasters in Korea. Also, most measures are concentrated on emergency recovery and hence insufficient effort is given to prevent secondary disasters. Therefore, it is necessary to improve the disaster management system for the geological hazards, not only for the engineering part, but also for the political and institutional areas.

\section{Geotechnical disasters in Korea}

The vulnerability against landslides is surely increasing because of landscape change and sometimes badly engineered cut slopes. As shown in Table 1, human casualties due to various natural disasters are not insignificant (modified after

Table 1: Human loss due to various natural disasters in Korea (modified after Park et al. [2]).

\begin{tabular}{l|l|l|l}
\hline Year & $\begin{array}{l}\text { Death by various } \\
\text { natural disasters }\end{array}$ & $\begin{array}{l}\text { Death by steep slope } \\
\text { disasters }\end{array}$ & Ratio (\%) \\
\hline \hline 1998 & 384 & 111 & 28.9 \\
\hline 1999 & 89 & 32 & 36.0 \\
\hline 2000 & 49 & 12 & 24.5 \\
\hline 2001 & 82 & 9 & 11.0 \\
\hline 2002 & 270 & 79 & 29.3 \\
\hline 2003 & 148 & 37 & 25.0 \\
\hline 2004 & 14 & 3 & 21.4 \\
\hline 2005 & 52 & 11 & 21.2 \\
\hline 2006 & 63 & 22 & 34.9 \\
\hline 2007 & 23 & 4 & 17.4 \\
\hline 2008 & 16 & 8 & 50.0 \\
\hline 2009 & 12 & 6 & 50.0 \\
\hline 2010 & 14 & 1 & 7.0 \\
\hline 2011 & 78 & 57 & 73.1 \\
\hline Total & 1,306 & 392 & 30.0 \\
\hline
\end{tabular}


Park et al. [2]). The most serious natural disaster in Korea is flash flood followed by landslide-related disasters. In the last 14 years from 1998 to 2011, disasters in steep slope areas killed 392 people.

Annual average of people killed by the slope-stability related disasters such as landslides and debris flows for the last 14 years is 28 in Korea. Even though many technologies are developed for landslide mitigation, the number of damage by landslide is not decreasing.

One of the reasons is because of reckless developments near housing areas and there are no regulations or enforcement to consider slope stability problems in the area and no warning systems for the residents near hillsides in Korea. Figs 1 and 2 show typical slope-stability related disasters in cut slope and natural terrain, respectively.
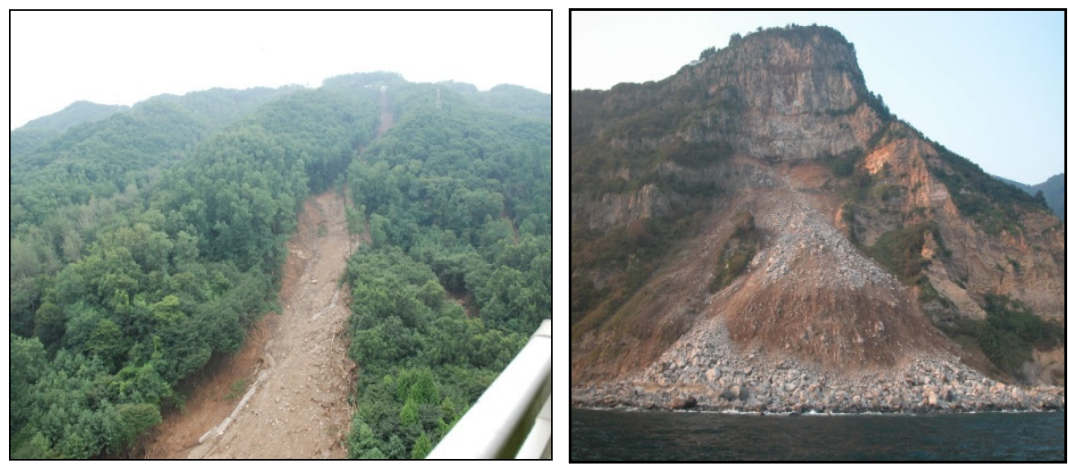

Figure 1: Destroyed residential area and beltway by natural slope failure.
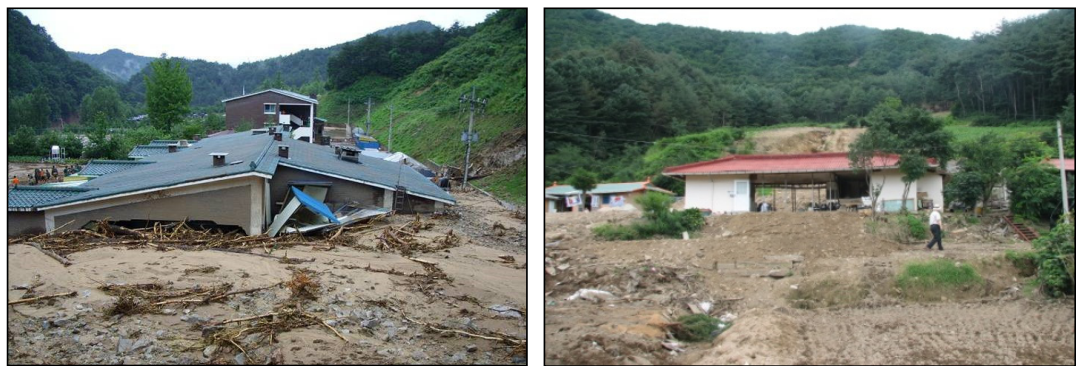

Figure 2: Buried houses by debris flow in Gangwon Province in 2006. 


\section{Suggestion of landslide early warning methods based on rainfall characteristics}

The early warning system for landslide disasters using rainfall data in this study is based on an empirical approach. It assumes that an area which experienced landslides with specific rainfall characteristics will experience similar landslides when similar rainfalls occur. If rainfall characteristics in a specific area can be observed in real time, an early warning for that specific area may be possible.

Therefore, before setting an early warning system, it is necessary to compile available information on previous landslide history with exact occurrence time and rainfall data. Previous rainfall accumulation data are analyzed and manipulated to find several rainfall characteristics, such as rainfall intensity and antecedent rainfall, and the relationship between rainfall and landslide occurrence. There are several steps or processes (Fig. 3) in the landslide early warning system before issuing landslide warning using various means of information dissemination to the local people such as sirens, automated phone calls, and mass media broadcasting.

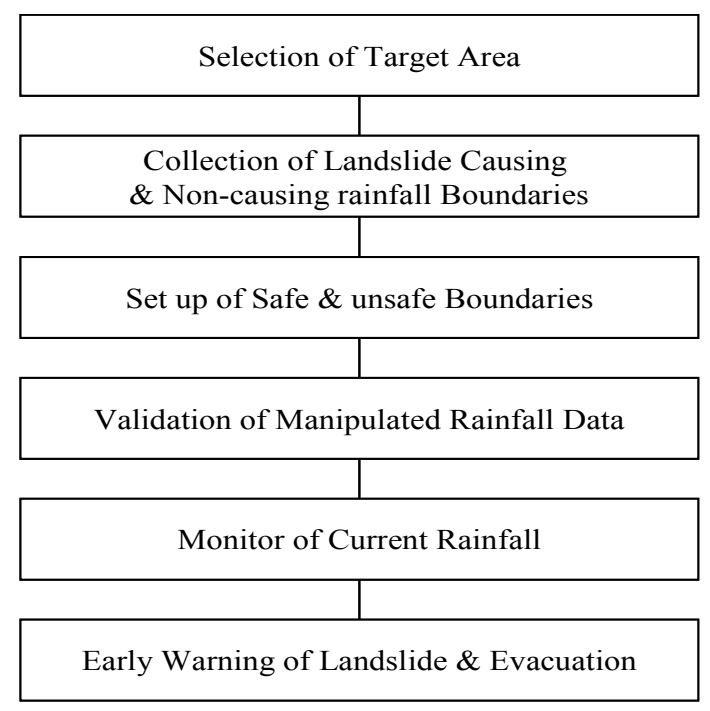

Figure 3: Flow of landslide early warning.

The first step is to find landslide-causing and landslide-non-causing rainfall data. This process is critical since the accuracy of early warning system is highly dependent on these data. Many data points can be depicted depending on the rainfall and landslide data availability. To consider the decaying effect of antecedent rainfall, half-life is applied depending on the site conditions. The half-life is the time period over which the rainfall amount in the soil or on the ground surface reduces to half reflecting the effect of rainfall dissipation. 
Most of the previous researches that adapted rainfall intensity and accumulative rainfall for the relationship between landslide occurrence and rainfall characteristics did not consider the effect of rainfall dissipation in the soil. As expressed by Eq. (1), the accumulative rainfall with decaying effect of antecedent rainfall can be defined as a working rainfall $\left(R_{w}\right)$.

$$
R_{w}=\sum \alpha_{i} \times R_{i} \text { and } \alpha_{i}=0.5^{i / T}
$$

where, $\alpha_{\mathrm{i}}$ is decay coefficient at $\mathrm{i}$ hours before a landslide; $R_{i}$ is rainfall intensity at $\mathrm{i}$ hours before a landslide; and $T$ is the half-life. The decay coefficient was estimated by tank model, which is one of the rainfall runoff models, and first layer and third layer in the tank model represent surface flow and ground infiltration, respectively (Sugawara et al. [3]).

In this study to consider antecedent accumulative rainfall amount and rainfall intensity (as shown in Figure 5), working rainfalls in abscissa and ordinate were calculated based on the half-lives of 72 hours and 1.5 hours, respectively, proposed by MLIT [4]. When the decay coefficient becomes less than 0.004 , the effect of antecedent rainfall is minimal. When applying 1.5 and 72 hour half-lives, the coefficients at 12 and 574 hours (about 24 days) before a landslide become less than 0.004 , respectively. To estimate more precise half-life representing soil characteristics in Korea, studies on the conversion of infiltration characteristics into applicable half-life will be needed based the relationship between rainfall and infiltration.

The second step is to draw a boundary or the critical line between rainfalls that caused and did not cause landslides. Generally, upper right side in the graph is unsafe zone, i.e. rainfall data which caused landslides are depicted. In this study landslide causing and non-causing rainfalls were surveyed in the field and analyzed using data from AWS located in the test site (Fig. 4). A linear line was selected between causing and non-causing area and other shapes of critical boundary can be considered.

The third step is to set up warning and evacuation lines in the same graph. Those lines are needed to be drawn considering enough evacuation time at a specific village. Enough evacuation time should reflect local characteristics such as how far the shelters are located, how many vulnerable people live in the town, and how fast the disaster information can be disseminated to the people after the warning. Those lines are usually predetermined, as in this study, based on the maximum half hour and maximum one hour rainfall, respectively. After establishing these lines and boundaries in a target area, the generated graph should be checked whether it is truly representing rainfall characteristics. If precise rainfall prediction is possible using radar or other instruments and exact time, when predicted rainfall will penetrate the critical boundary, can be estimated, those lines do not need to be predetermined.

The fourth step is to monitor current rainfall in a specific area where the graph is prepared for and analyze rainfall data drawing a tracking line. When the tracking line crosses the warning or evacuation line, an early warning and evacuation order can be disseminated. The final step in the landslide early warning system is to make actual warning for the people and make them 


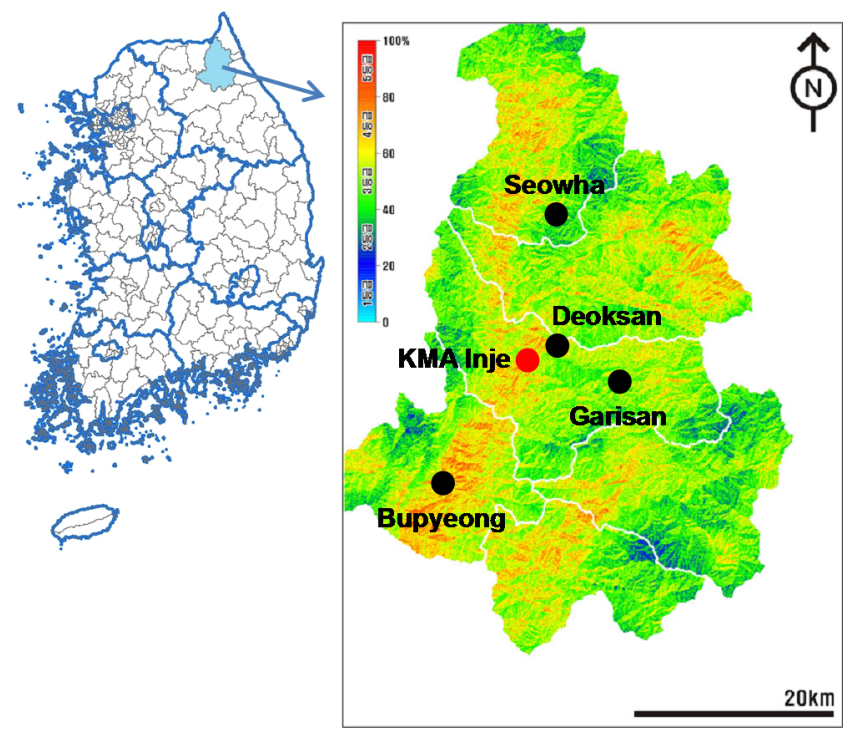

Figure 4: Location of rainfall monitoring system in the study area.

evacuate from dangerous landslide areas using various means of devices and laws and regulations.

In this study, tracking lines are drawn and monitored based on those real-time data according to the various preset lines such as critical lines, evacuation lines, and warning lines, which were selected considering maximum rainfalls in one and two hours, or maximum rainfalls in 30 minutes and one hour in the area. The tracking lines did not reach the warning lines which have been set up based on the maximum rainfalls in half hour and one hour. Also, all the tracking lines did not reach the critical lines regardless of the selection of the maximum rainfalls during the summer of 2008. This finding can be considered as a conclusion to support the validity of this study's approach, since there were no reported steep slope failures or landslide disasters in the study area during the summer of 2008 (NIDP [5]). The application of tracking line generated by the real-time data from Garisan, Bupyeong and Seowha elementary school are shown in Fig. 5 using maximum rainfalls in half hour and one hour for evacuation and warning lines, respectively. The filled and empty circles, and triangles in the figure represent rainfalls that actually caused human casualties, rainfall events with significant rainfall amounts without landslide occurrences, and rainfalls that caused landslides but with no human casualties, respectively. Critical lines, which are same for the three sites in the study area, are drawn at the boundaries of rainfalls that caused human casualties by landslides in the study area. Tracking lines in the figure, which are different from each other in the three sites of the study area, show several rainfall events in the study area during the summer of 2008. Since the decaying effects of rainfalls are reflected in the tracking lines, the lines can converge on zero point when a rainfall reduces or stops. This attribute of tacking lines can be applied when to cancel or call off warning and evacuation orders. 


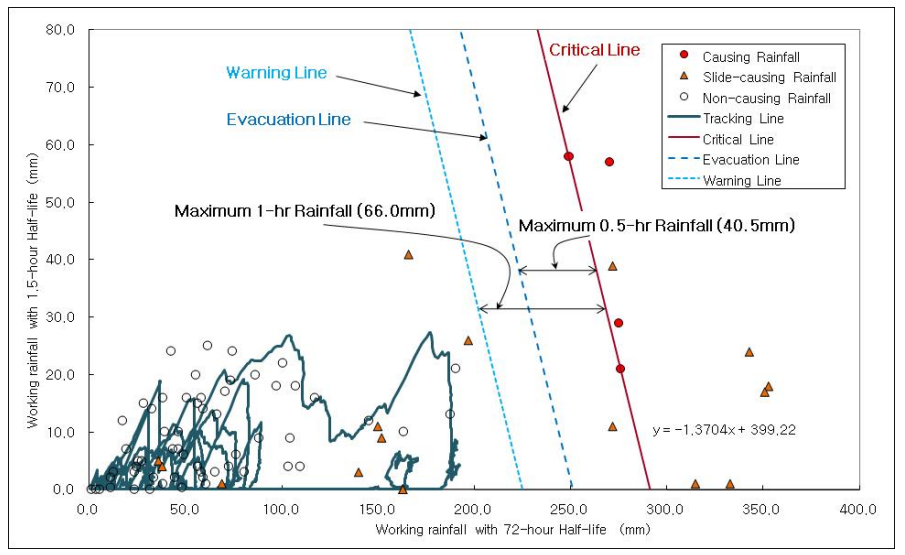

(a) Garisan elementary school area

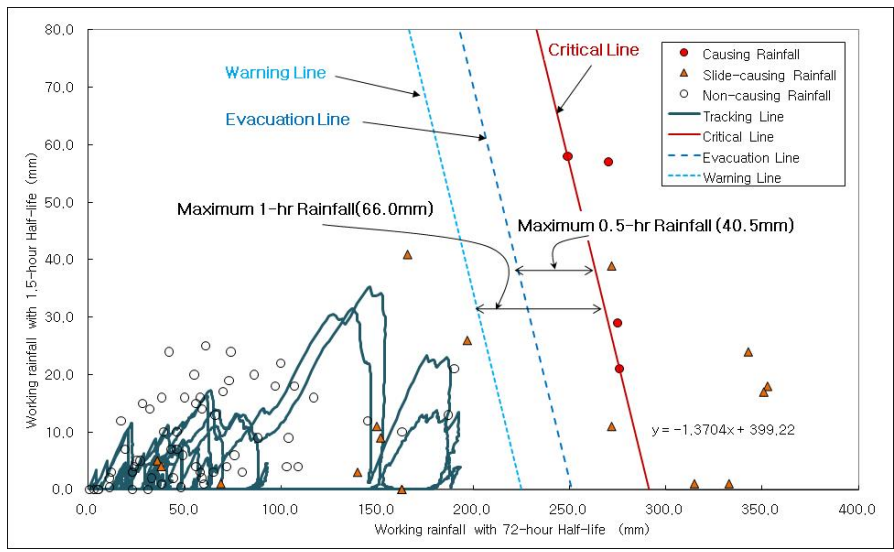

(b) Bupyeong elementary school area

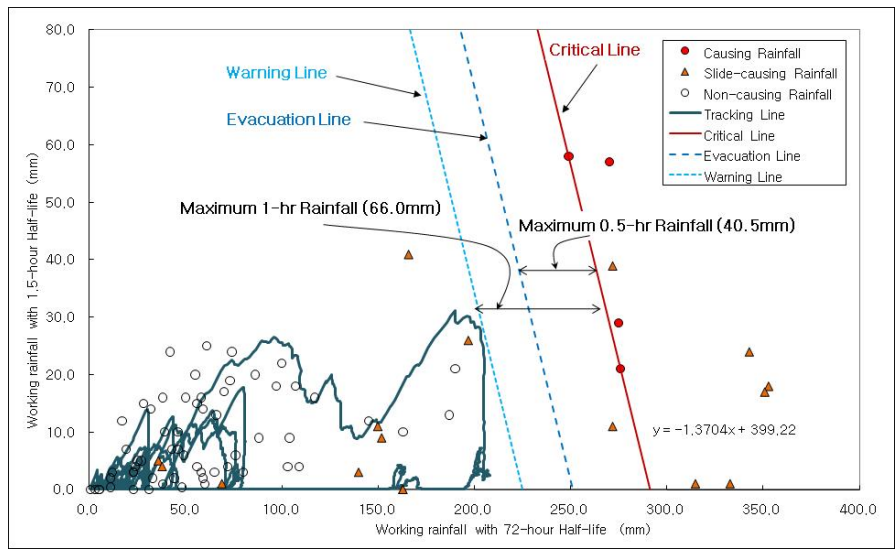

(c) Seowha elementary school area

Figure 5: Application of tracking line by the real-time data. 


\section{Conclusions}

Steep slope related disasters such as landslide occur almost every year in Korea causing social and economic disturbances. Fundamental countermeasures that can prevent steep slope related disasters are not always easy to implement due to uncertainty of disaster location and budget limitation. For an effective preparedness and response, landslide early warning system can be considered as a part of preemptive measures to minimize human casualties. Early detection of landslide indication in a broad natural terrain can be performed by monitoring of rainfall in real time or in near-real time.

In this study, three rainfall monitoring gauges have been installed in three different elementary schools in Seowha, Bupyeong, and Garisan to suggest warning criteria of landslides considered with local rainfall characteristics. The difference of rainfall data clearly explains that local rainfall patterns are strongly dependent upon topography, especially upon elevation in a mountain area as well as distance of each observation position during the summer. Therefore, it can be articulated that the density of AWS needs to be increased to be used as local standard for rainfall measurement unless rainfall measuring systems are installed independently for the operation of landslide early warning system. Tracking lines were drawn and monitored based on those real time data according to the various preset lines such as critical lines, evacuation lines, and warning lines, which were selected considering maximum rainfalls in one and two hours, or maximum rainfalls in half hour and one hour in the area. The tracking lines did not reach the warning lines which have been set up based on the maximum rainfalls in half hour and one hour. Also, all the tracking lines did not reach the critical lines regard-less of the selection of the maximum rainfalls during the summer of 2008 . This finding can be considered as a conclusion to support the validity of this study's approach, since there were no reported steep slope failures or landslide disasters in the study area during the summer of 2008.

\section{References}

[1] Park, D., Oh, J., Park, J., Chae, B., Slope Stability related Disasters and Regulatory Countermeasures in the Republic of Korea, IPL 2007 Symposium, Tokyo, Japan, Jan. 23, pp. 19-23, 2007.

[2] Park, D., Oh, J., Son, Y., Park, J., Lee, M., Steep Slope Management System in Korea, East Asia Landslides Symposium, Seoul, Korea, May 22-23, pp. 711, 2008.

[3] Sugawara M, Ozaki E, Watanabe I, Katsuyama Y, Tank Model and Its Application to Bird Creek, Wollombi Brook, Bikin River, Sanaga River and Nam Mune, Research Notes, National Research Center for Disaster Prevention, No. 11: pp. 1-64, 1974.

[4] MLIT, Guidelines for Development of Warning and Evacuation System against Sediment Disaster in Developing Countries, Infrastructure 
Development Institute, Ministry of Land Infrastructure and Transport, p. 116, 2004.

[5] NIDP, Study on the Applicability of an Early Warning system using Rainfall Data in Korea, Research Report, National Institute for Disaster Prevention, National Emergency Management Agency, p. 320 (in Korean), 2008. 